\title{
Oxidative Phosphorylation by Subcellular Particles from Yeast
}

\author{
By M. F. UTTER, D. B. KEECH AND P. M. NOSSAL \\ Departments of Biochemistry, Western Reserve University, Cleveland, U.S.A., \\ and University of Adelaide, Adelaide, Australia
}

(Received 3 May 1957)

The presence in Saccharomyes cerevisiae of refractile cytoplasmic granules with staining properties resembling those of mitochondria from animal cells has been reported by Mudd et al. (1951) and Hartman \& Liu (1954). On the basis of earlier evidence Lindegren (1949) had suggested that the cytoplasmic granules of yeast were mitochondrial in nature. This hypothesis has been supported by the findings of Slonimski \& Ephrussi (1949) that subcellular particles containing the enzymes concerned with terminal oxidation can be obtained by differential centrifuging of broken yeast cells. As further evidence Nossal (1954) obtained subcellular particles which contained several dehydrogenases and accessory enzymes of the Krebs cycle, and Linnane \& Still (1955) obtained a similar fraction able to oxidize pyruvate.

In the present report, the ability of subcellular particles from yeast to couple oxidation with phosphorylation has been demonstrated. This finding adds strong evidence in support of the view that the particles are related biochemically to mitochondria, since the ability to carry out respiratory-chain phosphorylation is perhaps the most definitive biochemical characteristic of mitochondria.

Oxidative phosphorylation by cell-free preparations from micro-organisms has been demonstrated previously by Pinchot \& Racker (1951), using Escherichia coli, by Pinchot (1953), using Alcaligenes faecalis, by Tissières \& Slater (1955), using Azotobacter vinelandii, by Brodie \& Gray $(1956 a, b)$, using Mycobacterium phlei, and by Nossal, Keech \& Morton (1956a), using Proteus vulgaris. In all these studies a soluble component has been implicated in the system employed, in contrast to the present studies with yeast, where washed particles were able to couple phosphorylation to oxidation without supplementation. In addition, the phosphorylation of the yeast particles was uncoupled by 2:4-dinitrophenol, whereas all of the bacterial systems with the exception of Mycobacterium phlei (Brodie \& Gray, 1956 a) are resistant to the action of this uncoupling agent.

\section{METHODS}

Preparation of particles. The bakers' yeast used in these experiments was obtained from Effront Ltd. (South Yarra, Victoria, Australia) or Red Star Yeast and Products Co.
(Milwaukee, U.S.A.) as the pressed, cooled cake and stored until use in a humid atmosphere at $2-5^{\circ}$. The yield and activity of the granules seems to depend somewhat on the age of the yeast, but generally satisfactory results were obtained any time from 3 to 10 days after harvesting.

The yeast was suspended evenly in cold $1 \% \mathrm{NaCl}$ soln. containing $0.01-0.001 \mathrm{~m}$-ethylenediaminetetra-acetic acid (EDTA), $\mathrm{pH} 6.5$, in a ratio of $1.5 \mathrm{~g}$. of yeast cake $/ 7 \mathrm{ml}$. of suspending fluid. The suspension (10-14 ml.) was added to pre-cooled glass beads (Ballotini no. 12; C. A. Brinkmann and Co., Great Neck, Long Island, New York) in a steel capsule, with $2 \mathrm{ml}$. of yeast suspension/g. of glass beads. The cells were disintegrated by shaking the capsules for 5-10 sec. at $0^{\circ}$ in a high-speed mechanical disintegrator (Nossal, 1953), at $6000 \mathrm{cyc} . / \mathrm{min}$. Such treatment ordinarily disrupts $20-40 \%$ of the yeast cells. If several capsules are available for use with the disintegrator about $90 \mathrm{~g}$. of yeast can be treated in $20 \mathrm{~min}$. by two operators.

The suspension of broken and whole cells was decanted from the glass beads and the suspension adjusted to $\mathrm{pH} 6 \cdot 8$ by the cautious addition of dil. $\mathrm{NaOH}$ soln. or $0.4 \mathrm{M}-2$ amino-2-hydroxymethylpropane-2:3-diol. Most whole cells and debris were removed by centrifuging for $10 \mathrm{~min}$. at $0^{\circ}$ and $1000 \mathrm{~g}$. This process was repeated to remove the remaining whole cells, or the same end was achieved by using only the top two-thirds of the supernatant resulting from the first centrifuging. The subcellular particles used in these studies were obtained by centrifuging the supernatant at $13000-23000 \mathrm{~g}$ for $15 \mathrm{~min}$. at $0^{\circ}$, in a refrigerated angle centrifuge. Since centrifuging at $10000 \mathrm{~g}$ is sufficient to recover most of the particles, variations above this value are unimportant. The pellet was resuspended in either $1 \%$ $\mathrm{NaCl}$ or $10 \%$ sucrose, each containing $0.001 \mathrm{~m}-\mathrm{EDTA}$, and the high-speed centrifuging step repeated. Ordinarily, the particles were washed only once, but the washing process can be repeated several times without significant change in the properties which have been studied. The washed pellet was carefully suspended in one-third to one-sixth of the original volume of $1 \% \mathrm{NaCl}$ or $10 \%$ sucrose, each containing $0.001 \mathrm{M}$-EDTA and $0.01 \mathrm{~m}$-sodium or -potassium phosphate (pH 6.7). As is discussed below, the properties of the particles are influenced somewhat by the nature of the washing and suspending media.

Manometric methods. About half of the experiments were conducted in Warburg flasks of approx. $20 \mathrm{ml}$. volume with a reaction mixture containing the following components in a total volume of $2.25 \mathrm{ml}$.: $50 \mu$ moles of sodium succinate, $2 \mu$ moles of adenosine triphosphate (ATP), $25 \mu$ moles of glucose, $20 \mu$ moles of $\mathrm{NaF}, 10 \mu$ moles of $\mathrm{MgCl}_{2}, 10 \mu$ moles of inorganic phosphate $\left(\mathrm{P}_{i}\right)$ (added with particles), $1 \mu$ mole of EDTA (added with particles), 0.3 unit of hexokinase, $50 \mu$ moles of glycylglycine or tris buffer ( $\mathrm{pH} \mathrm{6.7)}$ and $1 \mathrm{ml}$. of yeast particles with a protein content of 5-8 mg. The remaining experiments were 
carried out in vessels with a total volume of approx. $10 \mathrm{ml}$., 1.3-1.6 ml. being used as the total fluid volume and with the various components scaled down accordingly. In the experiments with particles from Red Star yeast, 2-4 mg. of bovine albumin was added since this substance gave increased $\mathrm{P} / \mathrm{O}$ values with most preparations. The source of yeast, disintegration time, washing and suspending media and deviations from the assay procedure just described are noted for individual experiments. Experiments were conducted at $22-23^{\circ}$, with air as the gas phase, with experimental flasks in duplicate and a single zero-time control for each pair.

All components of the assay mixture were added to the main chamber of the vessel and pre-cooled in ice before addition of the hexokinase and yeast particles. The centre wells of the vessels contained $20 \% \mathrm{KOH}$ soln. and fluted filter paper, and one side bulb contained $0.1 \mathrm{ml}$. of $10 \mathrm{~N}-$ $\mathrm{H}_{2} \mathrm{SO}_{4}$ or $0.2 \mathrm{ml}$. of $10 \%$ trichloroacetic acid. After addition of the particles the vessels were attached to the manometers as quickly as possible and equilibrated for $10 \mathrm{~min}$. at $22-23^{\circ}$. At the end of this period, the reaction was terminated in the control vessels by tipping in the acid from the side bulb and manometric measurements were initiated with the experimental vessels.

Determinations. Glucose 6-phosphate was determined spectrophotometrically by the use of the specific dehydrogenase on trichloroacetic acid filtrates neutralized with $\mathrm{NaOH}$ soln. Determinations were carried out at $30^{\circ}$ in $3 \mathrm{ml}$. of assay mixture containing $100 \mu \mathrm{moles}$ of glycylglycine ( $\mathrm{pH} \mathrm{7.4),} 3 \mu$ moles of $\mathrm{MnCl}_{2}, 0.6 \mu$ mole of triphosphopyridine nucleotide (TPN), $\mathbf{0 \cdot 2}$ unit of glucose 6-phosphate dehydrogenase and $0.03-0 \cdot 15 \mu$ mole of glucose 6phosphate. In our hands some preparations of the dehydrogenase were not satisfactory for this assay and consistently yielded low results, and it was necessary to test preparations carefully on known solutions before use. The presence of trichloroacetate slows the rate of production of reduced TPN somewhat and was not permitted to exceed $0.01 \mathrm{M}$. In general, best results were obtained from conditions arranged to permit completion of the reaction in $15 \mathrm{~min}$. or less.

Fumarate and malate were determined spectrophotometrically on trichloroacetic acid filtrates neutralized with $\mathrm{NaOH}$ soln., by using malic enzyme and fumarase and measuring production of reduced TPN. The assay mixture contained the following components in a volume of $3 \mathrm{ml}$.: $150 \mu$ moles of glycylglycine ( $\mathrm{pH} \mathrm{7 \cdot 4}$ ), $2 \mu$ moles of $\mathrm{MnCl}_{2}$, $0.6 \mu$ mole of TPN, $500 \mu$ moles of semicarbazide (pH 7.4), 0.4 unit of malic enzyme and 2 units of fumarase. The semicarbazide is required to prevent oxidation of reduced TPN by pyruvate and lactic dehydrogenase, since the latter is present as a contaminant of malic enzyme. At $30^{\circ} 0.05-$ $0.2 \mu$ mole of fumarate and malate can be estimated in a reaction period of about $30 \mathrm{~min}$. The preparations of malic enzyme employed contained as much lactic dehydrogenase [measured with reduced diphosphopyridine nucleotide (DPN) and pyruvate] as malic enzyme, and although reaction with reduced TPN is much slower and the pyruvate is bound by the semicarbazide, the values for malate and fumarate obtained were slightly less than predicted.

Orthophosphate $\left(\mathrm{P}_{i}\right)$ was determined on trichloroacetic acid filtrates by the method of Lohmann \& Jendrassik (1926) and protein was determined by the colorimetric biuret method of Robinson \& Hogden (1940), with crystalline bovine albumin (Armour) as a reference standard.

Enzymes. Hexokinase was prepared from yeast by following the procedure of Berger, Slein, Colowick \& Cori (1946) as far as step V, and stored in glucose and phosphate buffer (pH 5.4) at $-19^{\circ}$. As used in this paper, 1 unit of activity corresponds to the utilization of $1 \mu \mathrm{mole}$ of substrate or formation of $1 \mu$ mole of product/min. Before use the hexokinase was diluted with 9 vol. of $1 \%$ cold albumin and $0.1 \mathrm{ml}$. of the diluted solution was used in each reaction vessel. Malic enzyme was prepared from chicken liver as described by Utter \& Kurahashi (1954) and had a specific activity of $\mathbf{0 . 3}$ unit/mg. of protein. Fumarase was prepared from pig heart by the procedure of Massey (1955) as far as the first ammonium sulphate step after the gel treatment, and had a specific activity of 137 units/mg. of protein as measured by the spectrophotometric assay of Racker (1950). Glucose 6-phosphate dehydrogenase was prepared from yeast as described by Kornberg (1950) and had a specific activity of 1.5 units/mg. of protein.

Other materials. ATP, adenosine diphosphate (ADP), DPN and TPN were commercial materials obtained from Pabst Brewing Co., and cytidine diphosphate (CDP), guanosine diphosphate (GDP), uridine diphosphate (UDP), and inosine triphosphate (ITP) were commercial materials obtained from Sigma Chemical Co. 2-Deoxyglucose was synthesized by the method of Cramer (1955) and was generously provided by Mr P. Russell.

\section{RESULTS}

Components of the system. Particles obtained by differential centrifuging of disrupted yeast cells are able to couple phosphorylation with the oxidation of succinate (Table 1). Phosphorylation is greatly depressed or abolished by the omission of ATP, hexokinase or $\mathrm{MgCl}_{2}$, although oxidation is unaffected or even increased by the omission of these substances. The washed particles exhibit little phosphorylation or oxidation in the absence of added substrate. The presence of NaF had little effect upon the reaction in this experiment, but $\mathrm{NaF}$ was always included since early experiments had demonstrated the presence of adenosine triphosphatase in the particles.

\section{Table 1. Oxidative phosphorylation with yeast particles}

Particles were prepared from Effront Yeast by 10 sec. disintegration and washed and suspended in NaCl-EDTA. Approx. $8 \mathrm{mg}$. of protein was used in a total volume of $2.25 \mathrm{ml}$. with the assay procedure described in the text. The incubation time (not including equilibration period) was $30 \mathrm{~min}$.

\begin{tabular}{lccl}
\multicolumn{1}{c}{ Components } & $\begin{array}{c}\mathrm{O}_{2} \text { uptake } \\
(\mu \mathrm{g} . \text { atoms) }\end{array}$ & $\begin{array}{c}\mathrm{P}_{\text {i } \text { uptake }} \\
(\mu \text { moles })\end{array}$ & $\mathrm{P} / 0$ \\
All & $6 \cdot 35$ & $3 \cdot 93$ & $0 \cdot 62$ \\
ATP omitted & $6 \cdot 8$ & $1 \cdot 01$ & $0 \cdot 15$ \\
MgCl ${ }_{2}$ omitted & $8 \cdot 2$ & $1 \cdot 2$ & $0 \cdot 15$ \\
Hexokinase omitted & $7 \cdot 3$ & $-0 \cdot 88$ & 0 \\
NaF omitted & $6 \cdot 8$ & $4 \cdot 1$ & $0 \cdot 61$ \\
Succinate omitted & $0 \cdot 8$ & $0 \cdot 6$ & $0 \cdot 8$
\end{tabular}


Table 2. Uncoupling of phosphorylation by 2:4-dinitrophenol

Particles were prepared as described in Table 1 and assayed as described in the text, with an incubation period (not including equilibration period) of $20 \mathrm{~min}$.

$\begin{array}{cccc}\begin{array}{c}\text { 2:4-Dinitrophenol } \\ (\mathrm{mM})\end{array} & \begin{array}{c}\mathrm{O}_{2} \text { uptake } \\ (\mu \mathrm{g} . \text { atoms })\end{array} & \begin{array}{c}\mathrm{P}_{i} \text { uptake } \\ (\mu \text { moles })\end{array} & \mathrm{P} / \mathrm{O} \\ 0 & 3.4 & 2.25 & 0.66 \\ 0.036 & 3.45 & 1.6 & 0.46 \\ 0.091 & 3.4 & 0.85 & 0.25 \\ 0.18 & 3 \cdot 3 & 0.2 & 0.06 \\ 0.36 & 3.15 & -0.15 & 0\end{array}$

Over a large number of experiments, the $\mathrm{P} / \mathrm{O}$ ratios observed for the oxidation of succinate varied from 0.4 to $1 \cdot 2$, with the majority of values falling between $0 \cdot 6$ and $0 \cdot 9$. In occasional experiments there was failure to observe phosphorylation or even oxidation. The negative experiments were traced mainly to improper disintegration or $\mathrm{pH}$ control procedures. The variables controlling the yield and activity of the yeast particles and especially the $\mathrm{P} / \mathrm{O}$ ratios are only partially understood, but include; disintegration time; $\mathrm{pH}$ during isolation of the particles and during the assay procedure; the presence or absence of certain substances such as albumin, sucrose and $P_{i}$ during handling procedures; the maintenance of an optimum level of ADP during assay; and the age and condition of the yeast. The first two of these factors are dealt with in subsequent experiments in this paper and the third and fourth factors are under investigation at present. The $P / O$ values are considerably lower than reported for succinate oxidation with animal mitochondria (see, for example, Maley \& Plaut, 1953) and from this discrepancy, together with the observation (Table 1) that there is no obligatory coupling between oxidation and phosphorylation with the yeast particles, it might be inferred that the particles are not in their native state.

Uncoupling by 2:4-dinitrophenol. Although phosphorylation connected with respiration in several bacterial cell-free systems has been reported to be insensitive to 2:4-dinitrophenol, the yeast system is completely uncoupled by this substance (Table 2). The concentration required for complete uncoupling, $0 \cdot 3-0.5 \mathrm{~mm}$, is five- to ten-fold higher than that reported for animal mitochondria by Cross, Taggart, Covo \& Green (1949). In agreement with the finding that the presence of an ATP. trapping system does not stimulate oxidation (Table 1), the addition of 2:4-dinitrophenol fails to enhance the oxidation of succinate, in fact, at higher concentrations, oxidation of succinate is slightly inhilsited.

The effect of 2:4-dinitrophenol can be prevented by its removal from the particles by washing
(Table 3). In these experiments after the whole cells and debris had been removed by preliminary centrifuging, $0.6 \mathrm{~mm}$-2:4-dinitrophenol was added to one half of the supernatant but the other half was untreated. Both portions were then centrifuged to obtain particles, which were washed with NaCl-EDTA solution and resuspended in the same medium. When tested with succinate, the particles obtained from the 2:4-dinitrophenol-treated supernatant had lost some respiratory activity, but the $\mathrm{P} / \mathrm{O}$ value was slightly higher than that of the control particles. The oxidative phosphorylation of both types of granules was uncoupled by 2:4dinitrophenol added during the assay.

Variations in the preparation of the particles. The duration of the disintegration period has a marked effect on the particles subsequently obtained (Table 4). The second and third columns of Table 4 show the protein content of the initial supernatant fluids and the amount of protein obtained by centrifuging respectively. The fourth column shows the oxidative activity exhibited by similar quantities of particles obtained with the various shaking periods. There is some variation in oxidative activity, but the most notable effect is a constant decrease in the $\mathrm{P} / \mathrm{O}$ ratio as the period of shaking is increased. The loss of phosphorylative activity may be due to further disruption of the particles, since Nossal (1954) has found that with longer periods of shaking several enzymes, including fumarase, aconitase and ethanol dehydrogenase, tend to move from the particulate fraction to the supernatant fraction.

The composition of the medium in which the yeast cells are disrupted and in which the particles are washed and suspended has a considerable influence upon the properties of the particles. In these experiments $1 \% \mathrm{NaCl}$ soln. containing EDTA has been generally employed as the medium for disintegration. Particles obtained by disintegration in alkaline phosphate have been found by Nossal et al. $(1956 a)$ to be able to oxidize a number of substrates including succinate. However, phosphate has been shown to have a deleterious effect on mitochondrial integrity (Hunter \& Ford, 1955) and the phosphorylation of yeast particles is also adversely affected by the presence of phosphate, so this disintegration procedure is unsuitable for the present studies. Preliminary studies with $0.9 \%$ $\mathrm{KCl}$ soln. yielded particles with considerable endogenous activity and with lower $\mathrm{P} / \mathrm{O}$ values than similar preparations obtained with $\mathrm{NaCl}$. Linnane \& Still (1955) used sucrose for the disintegration of yeast cells and obtained particles capable of carrying out the complete oxidation of pyruvate. Sucrose has not been investigated extensively in the present studies, but the results available indicate that particles obtained from disintegration in

Bioch. 1958, 68 


\section{Table 3. Reversibility of inhibition by 2:4-dinitrophenol}

Particles were prepared from Effront Yeast by 10 sec. disintegration. To one half of the supernatant 2:4-dinitrophenol was added to give a final concentration of $0.6 \mathrm{mM}$ and the other half was untreated. Particles were recovered from both portions by centrifuging at $20000 \mathrm{~g}$, washed with $\mathrm{NaCl}-\mathrm{EDTA}$, resuspended in $\mathrm{NaCl}-\mathrm{EDTA}$ and assayed for $30 \mathrm{~min}$. as described in the text.

Treatment of
particle
None
None
2:4-Dinitrophenol
2:4-Dinitrophenol

2:4-Dinitrophenol
(mM)
0
0.54
0
0.54

\begin{tabular}{|c|}
\hline $\begin{array}{c}\mathrm{O}_{2} \text { uptake } \\
(\mu \mathrm{g} \text {. atoms })\end{array}$ \\
\hline $\begin{array}{l}7 \cdot 3 \\
6 \cdot 2 \\
4 \cdot 4 \\
4 \cdot 6\end{array}$ \\
\hline
\end{tabular}

$\begin{array}{cl}\mathrm{P}_{i} \text { uptake } & \\ (\mu \text { moles }) & \mathrm{P} / \mathrm{O} \\ 3 \cdot 2 & 0.44 \\ 0 & 0 \\ 2 \cdot 4 & 0.55 \\ 0.4 & 0.07\end{array}$

Table 4. Effect of disintegration time

Particles were prepared from Red Star Yeast and were washed and suspended in sucrose-EDTA. Particles equivalent to $2.5 \mathrm{mg}$. of protein were assayed as described in the text, for $30 \mathrm{~min}$. in a total volume of $1.3 \mathrm{ml}$.

$\begin{array}{cccc}\text { Disintegration } \begin{array}{c}\text { Protein* (mg.) } \\ \text { time } \\ \text { (sec.) }\end{array} & \begin{array}{c}\text { Initial } \\ \text { supernatant }\end{array} & \text { Particles } & \begin{array}{c}\text { O. uptake } \\ (\mu \mathrm{g} . \text { atoms) }\end{array} \\ 5 & 6.4 & 1.4 & 2.34 \\ 10 & 10.2 & 2.7 & 1.58 \\ 20 \dagger & 15.1 & 5.0 & 1.74 \\ 40 \dagger & 20.7 & 5.7 & 1.93\end{array}$

* Yield/ml. of initial supernatant from centrifuging at $1000 \mathrm{~g}$.

$\begin{array}{cc}\mathbf{P}_{\boldsymbol{i}} \text { uptake } & \\ \text { ( } \boldsymbol{\text { moles } )} & \mathrm{P} / \mathrm{O} \\ \mathbf{l} \cdot 29 & 0.55 \\ \mathbf{0 . 7 3} & 0 \cdot 46 \\ \mathbf{0 . 5 4} & 0 \cdot 31 \\ 0.40 & 0 \cdot 21\end{array}$

$\dagger$ With cooling after each 10 sec. interval. sucrose exhibit $\mathrm{P} / \mathrm{O}$ values of the same general range as those obtained by disruption in $\mathrm{NaCl}$. The presence of EDTA aids greatly in the stabilization of yeast particles, as has been reported for animal mitochondria (Slater \& Cleland, 1952).

Two different washing and suspending media have been employed in these studies : $1 \% \mathrm{NaCl}$ and $10 \%$ sucrose, each containing 0.001 M-EDTA. Although the particles obtained by these alternative procedures have generally similar characteristics, particles prepared in sucrose seem to have a higher activity/mg. of protein, although $\mathrm{P} / \mathrm{O}$ values are no higher than with granules prepared in $\mathrm{NaCl}$. The particles prepared in sucrose appear to be associated to some degree with several pyridine nucleotide dehydrogenases, whereas the particles prepared in $\mathrm{NaCl}$ are virtually free from the same dehydrogenases (see below). The presence of sucrose or albumin or both during the washing and suspending procedures seems to stabilize the particles, and the influence of these and other substances is under further investigation.

Sedimentation behaviour of yeast particles. In the foregoing experiments the particulate fractions were obtained from the centrifugal interval between $1000 \mathrm{~g}$ and $13000-23000 \mathrm{~g}$. The fractions used possibly contained sedimentable material of greatly varying size and activity. To determine whether the oxidative and phosphorylative activities were correlated in any regular fashion with sedimentation properties, fractionation studies were attempted. Sedimentable material was collected by centrifuging for successive $15 \mathrm{~min}$. periods at 5000, 10000 and $23000 \mathrm{~g}$. Each centrifuging was carried out in $0.25 \mathrm{M}$-sucrose in an angle-head centrifuge, and the relative centrifugal forces as given apply to the bottom of the centrifuge tubes. After washing, each fraction was tested on succinate along with another portion which was obtained by centrifuging directly at $23000 \mathrm{~g}$ (Table 5). Fraction $A$, representing material thrown down over the entire range from 1000 to $23000 \mathrm{~g}$, gives essentially the same results as the material sedimented in a similar time interval at $5000 \mathrm{~g}$ (fraction $B$ ). The material sedimented between 5000 and $10000 \mathrm{~g}$ (fraction $C$ ) has a slightly lower oxidative activity and a slightly lower $\mathrm{P} / \mathrm{O}$ value. Fraction $D$, representing the material sedimentable with difficulty shows a markedly lower oxidative activity, although the $\mathrm{P} / \mathrm{O}$ value is still comparable. From the second column of Table 5, in which the yield of particles is given, it can be seen that about $55 \%$ of the sedimentable protein is obtained in fraction $B$, about $25 \%$ in fraction $C$ and somewhat less in fraction $D$. According to these preliminary studies, there is no indication of a significant fractionation of the material responsible for oxidative phosphorylation.

The experiments shown in Table 5, and several other attempted fractionations, indicate that the active material is distributed over a considerable range of centrifugal behaviour, and that half or more of the sedimentable protein can be obtained in $15 \mathrm{~min}$. by centrifugal forces not exceeding 


\section{Table 5. Centrifugal fractionation of particles}

Particles were obtained from Red Star Yeast by 5 sec. disintegration and the supernatant from the initial centrifuging at $1000 \mathrm{~g}$ was fractionated as described in the text after the addition of sucrose to a concentration of $0.25 \mathrm{M}$. Each fraction was washed and suspended in sucrose-EDTA and incubated with succinate for $30 \mathrm{~min}$. in a total volume of 1.3 ml. Fractions $A$ and $B$ were assayed with $2.2 \mathrm{mg}$. of protein/vessel and $C$ and $D$ with $2.9 \mathrm{mg}$. of protein/vessel. Here and in Table 6 the incubation time does not include the equilibration period.

\begin{tabular}{|c|c|c|c|c|c|}
\hline Fraction & $\begin{array}{c}10^{-3} \times \text { Relative } \\
\text { centrifugal force } \\
(g)\end{array}$ & $\begin{array}{l}\text { Yield* } \\
\text { (mg.) }\end{array}$ & $\begin{array}{c}\mathrm{O}_{2} \text { uptake } \\
(\mu \mathrm{g} . \text { atoms })\end{array}$ & $\underset{(\mu \text { moles })}{P_{i} \text { uptake }}$ & $\mathrm{P} / \mathrm{O}$ \\
\hline $\begin{array}{l}A \\
B \\
C \\
D\end{array}$ & $\begin{array}{c}1-23 \\
1-5 \\
5-10 \\
10-23\end{array}$ & $\begin{array}{l}0.72 \\
0.45 \\
0 \cdot 2 \\
0 \cdot 14\end{array}$ & $\begin{array}{l}3 \cdot 05 \\
3 \cdot 15 \\
3 \cdot 14 \\
1 \cdot 47\end{array}$ & $\begin{array}{l}2 \cdot 26 \\
2 \cdot 31 \\
1 \cdot 98 \\
0.93\end{array}$ & $\begin{array}{l}0.74 \\
0.73 \\
0.73 \\
0.63\end{array}$ \\
\hline
\end{tabular}

$5000 \mathrm{~g}$. The 'respiratory granules' of yeast, as identified by microscopic observation (Mudd et al. 1951), have been reported to range from 0.3 to $1 \mu$ in diameter. Linnane \& Still (1955) estimated that the particles obtained by disintegration in sucrose were about $0 \cdot 3 \mu$ in diameter, although the fraction used was precipitated between 3000 and $25000 \mathrm{~g}$ and no fractionation studies were reported. These observations can be reconciled with the present studies by assuming that the active particles are small in size but are associated to varying degrees with larger structural elements of the yeast cell under the disintegration conditions used. It should be noted that the period of shaking was only 5 sec. in these experiments and that it is possible that longer periods of shaking would change the centrifugal distribution. A second possible explanation for the present results is that the active particles are small but tend to aggregate under the conditions used for isolation. Preliminary studies of some of the fractions by electron and phase-contrast microscopy lends some support to the hypothesis that small particles are attached to a larger structural element such as a vacuolar membrane.

Whole yeast cells can be essentially eliminated from consideration in these studies, since parallel experiments with yeast suspensions treated in the usual way except for omission of disintegration show that at most 1-2\% of the sedimented protein is in the form of unbroken cells. Direct examination with the phase-contrast microscope also indicates that the whole cells are very few in number in the fractions.

Effect of pH. Since oxidation and phosphorylation are not obligatorily associated in the yeast particles, it is possible to investigate the two processes as separate phenomena. The effect of variations in $\mathrm{pH}$ during the assay is shown in Table 6. The results show that the oxygen uptake increases markedly as the $\mathrm{pH}$ is increased from $6 \cdot 3$ to $7 \cdot 5$, whereas phosphorylation shows a broad maximum between $6 \cdot 6$ and $7 \cdot 5$. On the basis of
Table 6. Effect of $\mathrm{pH}$

Particles were prepared from Effront Yeast by 10 sec. disintegration and the particles isolated without the usual neutralization. The particles were divided into portions and washed in $\mathrm{NaCl}-\mathrm{EDTA}$ containing $0.016 \mathrm{M}$-sodium phosphate of the appropriate $\mathrm{pH}$ and suspended in the same medium. Particles equivalent to $5 \mathrm{mg}$. of protein were incubated with succinate for $20 \mathrm{~min}$. with components as described in the text except that glycylglycine and succinate were adjusted to the $\mathrm{pH}$ indicated.

\begin{tabular}{|c|c|c|c|c|}
\hline $\begin{array}{c}\text { Expt. } \\
\text { no. }\end{array}$ & $\mathrm{pH}$ & $\begin{array}{c}\mathrm{O}_{2} \text { uptake } \\
(\mu \mathrm{g} . \text { atoms })\end{array}$ & $\begin{array}{c}\mathrm{P}_{i} \text { uptake } \\
(\mu \text { moles })\end{array}$ & $\mathbf{P} / 0$ \\
\hline 1 & $\begin{array}{l}6 \cdot 3 \\
6 \cdot 6 \\
6 \cdot 9\end{array}$ & $\begin{array}{l}2 \cdot 9 \\
\mathbf{4} \cdot 35 \\
\mathbf{5} \cdot 0\end{array}$ & $\begin{array}{l}1 \cdot 8 \\
3 \cdot 0 \\
3 \cdot 0\end{array}$ & $\begin{array}{l}0 \cdot 62 \\
0 \cdot 69 \\
0 \cdot 60\end{array}$ \\
\hline 2 & $\begin{array}{l}6 \cdot 6 \\
7 \cdot 2 \\
7 \cdot 5\end{array}$ & $\begin{array}{l}3 \cdot 6 \\
6 \cdot 65 \\
7 \cdot 45\end{array}$ & $\begin{array}{l}2 \cdot 8 \\
3 \cdot 5 \\
3 \cdot 1\end{array}$ & $\begin{array}{l}0.78 \\
0.52 \\
0.41\end{array}$ \\
\hline
\end{tabular}

$\mathrm{P} / \mathrm{O}$ ratios, the $\mathrm{pH}$ range of $6 \cdot 6-6 \cdot 9$ is the most satisfactory and has been used in these studies.

Specificity of phosphate acceptor. The yeast particles seem to have an absolute specificity for ADP as the phosphate acceptor (Table 7). Only ADP or ATP (which in the presence of hexokinase and glucose is converted into ADP) can cause phosphorylation, and CDP, UDP, GDP and ITP are all completely inactive. The presence of the other nucleoside diphosphates has little or no inhibition of phosphorylation in the presence of ADP and the oxygen uptake is not affected. The specificity for ADP is in agreement with the results of Cooper \& Lehninger (1956), who found that ADP is the obligatory acceptor for phosphorylation with mitochondrial fragments of rat liver. Herbert, Potter \& Takagi (1955) have reported that mitochondria from rat liver can phosphorylate UDP to UTP during oxidation, but it is by no means certain that UDP is the primary acceptor.

In Expt. 3, of Table 7, it is shown that adenosine monophosphate (AMP) cannot replace ADP as the acceptor in the yeast system. Preliminary studies indicate that at concentrations of ADP lower than 
used in Table 7, AMP inhibits phosphorylation. This finding is apparently in distinct contrast with studies with animal mitochondria (Lehninger, 1953), where AMP can serve successfully as the phosphate acceptor, presumably through the mediation of myokinase, in the absence of NaF.

Products formed during oxidation of succinate. Under the conditions of the present studies the oxidation of succinate is essentially a one-step reaction to fumarate. In the experiments of Table 8, the accumulation of fumarate and malate is compared with the consumption of oxygen and $P_{i}$. Since it had been found in experiments not shown here that particles prepared by washing with sucrose contained appreciable quantities of glucose 6-phosphate dehydrogenase, parallel experiments were included here in which 2-deoxyglucose was substituted for glucose in the ATP-trapping system. Woodward \& Hudson (1955) have shown that yeast hexokinase phosphorylates 2-deoxy. glucose and glucose at comparable rates. However, the further metabolism of the phosphorylated product should be much slower with 2-deoxy sugar, and thus the latter is the preferred acceptor in many situations.

\section{Table 7. Specificity of phosphate acceptor}

Particles were prepared and tested as described in Table 1, except that $2 \mu$ moles of the various nucleoside polyphosphates were added as indicated.

$\begin{array}{clccl}\begin{array}{c}\text { Expt. } \\ \text { no. }\end{array} & \text { Acceptor } & \begin{array}{c}\mathrm{O}_{2} \text { uptake } \\ (\mu \mathrm{g} . \text { atoms })\end{array} & \begin{array}{c}\mathrm{P}_{i} \text { uptake } \\ (\mu \text { moles })\end{array} & \mathrm{P} / 0 \\ 1 & \text { ATP } & 6 \cdot 8 & 3 \cdot 0 & 0 \cdot 44 \\ & \text { ADP } & 5 \cdot 5 & 2 \cdot 9 & 0 \cdot 53 \\ & \text { UDP } & \mathbf{6 \cdot 4} & 0 & 0 \\ & \text { UDP + ADP } & 7 \cdot 5 & 2 \cdot 6 & 0 \cdot 35 \\ & \text { CDP } & 6 \cdot 9 & 0 & 0 \\ & \text { CDP + ADP } & 7 \cdot 6 & 3 \cdot 2 & 0 \cdot 42 \\ 2 & \text { ADP } & 7 \cdot 1 & 3 \cdot 4 & 0 \cdot 48 \\ & \text { ITP } & 6 \cdot 4 & 0 & 0 \\ & \text { ITP+ADP } & 8 \cdot 3 & 3 \cdot 4 & 0 \cdot 41 \\ & \text { GDP } & 6 \cdot 4 & 0 & 0 \\ & \text { GDP + ADP } & \mathbf{8 \cdot 5} & 3 \cdot 9 & 0 \cdot 46 \\ 3 & \text { ADP } & 6 \cdot 0 & 4 \cdot 1 & 0 \cdot 68 \\ & \text { AMP } & 4 \cdot 8 & 0 & 0 \\ & \text { AMP + ADP } & 5 \cdot 5 & 4 \cdot 5 & 0 \cdot 82\end{array}$

From the first two lines of Table 8, it is seen that there is little consumption of oxygen or $P_{i}$ in the absence of succinate. After a $30 \mathrm{~min}$. reaction period, a considerable portion of the glucose 6phosphate which had been formed during the equilibration period by hexokinase action had disappeared. From this amount, $0.93 \mu$ mole, it might be expected that the oxygen uptake in line 1 should be at least $0.45 \mu \mathrm{mole}$ instead of $0.2 \mu \mathrm{g}$. atom, but these values are so small as to be within experimental error. With glucose as the acceptor about $70 \%$ of the theoretical amount of fumarate and malate predicted from oxygen uptake is found. With 2-deoxyglucose the amount of fumarate and malate rose to $85 \%$ of theoretical. As discussed under Methods, the determination employed gives slightly low values for malate and fumarate, and it seems safe to conclude that succinate is oxidized mainly if not entirely to fumarate and malate. Nossal et al. (1956a) found that fractions from yeast capable of oxidizing several substrates oxidized malate poorly, if at all.

The $\mathrm{P} / \mathrm{O}$ value with 2-deoxyglucose is higher than with glucose (Table 8), a consistent finding with sucrose-washed granules which supports the idea that glucose 6-phosphate is further metabolized. On the basis of the glucose 6-phosphate changes in the presence and absence of succinate, it can be calculated that $1.37 \mu$ moles of glucose 6-phosphate were formed in the succinate experiment. This value is in good agreement with the $P_{i}$ uptake of $1.21 \mu \mathrm{moles}$, although this calculation rests on the assumption that glucose 6-phosphate utilization is unaffected by the presence of succinate.

By using particles prepared by washing and suspending in $\mathrm{NaCl}$ rather than sucrose, it has been possible to demonstrate more clearly that glucose 6-phosphate is the major phosphorylated product arising from phosphate as a result of succinate oxidation (Table 9). The changes in oxygen uptake, $P_{i}$, and glucose 6-phosphate in the presence and absence of succinate are shown. Considerable glucose 6-phosphate was present at the start of the experiment even in the absence of

Table 8. Products of the oxidation of succinate

Particles were prepared from Red Star Yeast by 5 sec. disintegration and washed and suspended in sucrose-EDTA. Particles representing $3.5 \mathrm{mg}$. of protein were used in a total volume of $1.3 \mathrm{ml}$. When 2-deoxyglucose was used as the acceptor of $P_{i}$, hexokinase was dialysed free from glucose. All values represent changes during $30 \mathrm{~min}$. reaction period.

\begin{tabular}{|c|c|c|c|c|c|c|}
\hline Substrate & $P_{i}$ acceptor & $\begin{array}{l}\mathrm{O}_{2} \text { uptake } \\
(\mu \mathrm{g} . \text { atoms) }\end{array}$ & $\begin{array}{c}P_{i} \text { uptake } \\
(\mu \text { moles })\end{array}$ & $\mathbf{P} / 0$ & $\begin{array}{c}\text { malate } \\
\text { produced } \\
(\mu \text { moles })\end{array}$ & $\begin{array}{c}\text { 6-phosphate } \\
\text { produced } \\
\text { ( } \mu \text { moles })\end{array}$ \\
\hline None & Glucose & 0.2 & 0.05 & $0 \cdot 25$ & - & -0.93 \\
\hline None & 2-Deoxyglucose & $0 \cdot \overline{1}$ & 0 & 0 & - & - \\
\hline Succinate & Glucose & $2 \cdot 35$ & $1 \cdot 21$ & 0.51 & $1 \cdot 64$ & $0 \cdot 44$ \\
\hline Succinate & 2-Deoxyglucose & $2 \cdot 2$ & $1 \cdot 67$ & $0 \cdot 75$ & $1 \cdot 82$ & - \\
\hline
\end{tabular}


substrate because of the prior action of hexokinase on glucose and ATP. The amount of glucose 6phosphate increased only slightly in the absence of succinate during the experimental period, indicating that no significant correction for myokinase activity is required. When succinate was present, glucose 6-phosphate increased by $1.41 \mu$ moles during the experimental period as compared with $1.98 \mu$ moles of $\mathrm{P}_{i}$ utilized. These results show the relative stability of glucose 6-phosphate with particles prepared in $\mathrm{NaCl}$ in contrast with particles washed and suspended in sucrose (Table 8). This result agrees with other evidence that particles prepared in $\mathrm{NaCl}$ are relatively free from pyridine nucleotide dehydrogenases.

It was shown in Table 1 that the absence of hexokinase markedly decreased phosphorylation. The experiments of Table 10 show that both hexokinase and glucose must be present for phosphorylation to occur to any significant degree. The residual phosphorylation observed in the absence of hexokinase or glucose may be due to small amounts of hexokinase and $\mathbf{P}_{i}$ acceptors associated with particles which have been washed only once. The glucose 6-phosphate formed in this experiment is given for purposes of comparison with Table 9 .

The combination of observations that the oxidation of succinate is mainly a one-step reaction, that phosphorylation is dependent on the presence of succinate, glucose and hexokinase, and that glucose 6-phosphate is the major phosphorylated product indicate that, in the reaction under study, ATP is produced from $P_{i}$ and ADP during the oxidation of succinate to fumarate. Since no substrate level phosphorylation is known for this oxidative step, the observations provide evidence independent of the 2:4-dinitrophenol experiments that the phosphorylation under study is associated with electron transport to oxygen.

Oxidation of other substrates. All the previous experiments have been concerned with the oxidation of succinate. Attempts have been made to substitute other substrates including lactate, $\alpha$ oxoglutarate, ethanol, isocitrate, $\beta$-hydroxybutyrate and malate. The situation is complicated by the fact that particles prepared from yeast by different procedures possess different abilities to oxidize various substrates. Nossal et al. (1956a) have found that particles obtained by the disruption of yeast in phosphate $(\mathrm{pH} 7 \cdot 6)$ can oxidize ethanol, isocitrate, $\alpha$-oxoglutarate and lactate, but not malate. For reasons discussed above, particles prepared in phosphate are not suitable for studies of oxidative phosphorylation. Nossal, Keech \& Utter (1956b) found that particles prepared by disruption in $\mathrm{NaCl}$ and washing in sucrose, such as have been used in this study, are also able to oxidize ethanol, isocitrate, $\alpha$-oxoglutarate and lactate when appropriate cofactors are provided, but not malate or $\beta$-hydroxybutyrate. Some phosphorylation accompanied these oxidation reactions. However, the results of these experiments are highly variable and generally suggest that factors necessary for oxidation are retained to varying degrees in different batches of particles. Particles prepared by washing and suspending in $\mathrm{NaCl}$ oxidize only succinate and lactate.

It may be inferred that the particles prepared in phosphate have various dehydrogenase activities and probably contain other factors necessary for

Table 9. Formation of glucose 6-phosphate

Particles were prepared from Red Star Yeast by 5 sec. disintegration and washed and suspended in NaCl-EDTA. Approx. $4.5 \mathrm{mg}$. of protein was used in a total volume of $1.3 \mathrm{ml}$. The difference in the concentration of $P_{i}$ in the two zerotime flasks is due to phosphorylation occurring in the flask with substrate during the equilibration period.

\begin{tabular}{|c|c|c|c|c|c|c|c|}
\hline Substrate & $\begin{array}{c}\text { Incubation } \\
\text { time } \\
\text { (min.) }\end{array}$ & $\begin{array}{c}\mathrm{O}_{2} \text { uptake } \\
(\mu \mathrm{g} . \text { atoms })\end{array}$ & $\underset{(\mu \text { moles })}{\mathrm{P}_{i}}$ & $\underset{(\mu \text { moles })}{\Delta \mathrm{P}_{i}}$ & $\begin{array}{c}\text { Glucose } \\
\text { 6-phosphate } \\
\text { ( } \mu \text { moles) }\end{array}$ & $\begin{array}{c}\Delta \text { Glucose } \\
\text { 6-phosphate } \\
\text { ( } \mu \text { moles })\end{array}$ & $\mathrm{P} / \mathrm{O}$ \\
\hline None & 0 & - & $5 \cdot 0$ & - & 0.85 & - & - \\
\hline None & 25 & $0 \cdot 1$ & $5 \cdot 0$ & 0 & 0.99 & $+0 \cdot 14$ & 0 \\
\hline Succinate & 0 & - & $4 \cdot 03$ & - & $1 \cdot 30$ & - & - \\
\hline Succinate & 25 & $2 \cdot 89$ & $2 \cdot 05$ & -1.98 & $2 \cdot 71$ & $+1 \cdot 41$ & $0 \cdot 69$ \\
\hline
\end{tabular}

Table 10. Requirement for hexokinase and glucose

Particles were prepared as described in Table 9 and assayed with succinate for 30 min. with $3 \mathrm{mg}$. of protein/vessel in a total volume of $1.3 \mathrm{ml}$. Hexokinase (dialysed) or glucose was omitted as indicated.

\begin{tabular}{lcccc}
\multicolumn{1}{c}{ Components } & $\begin{array}{c}\mathrm{O}_{2} \text { uptake } \\
(\mu \mathrm{g} \cdot \text { atoms })\end{array}$ & $\begin{array}{c}\mathrm{P}_{\boldsymbol{i}} \text { uptake } \\
(\mu \mathrm{moles})\end{array}$ & $\begin{array}{c}\text { 6-phosphate } \\
\text { produced } \\
(\mu \mathrm{moles})\end{array}$ \\
All & 1.65 & 1.44 & 0.87 & $\mathbf{1 . 2 1}$ \\
Hexokinase omitted & 1.51 & 0.22 & 0.15 & - \\
Glucose omitted & 1.65 & 0.17 & 0.13 & - \\
Hexokinase and glucose omitted & 1.96 & 0.39 & 0.2 & -
\end{tabular}

Glucose

6-phosphate

produced

$1 \cdot 21$

$0 \cdot 13$

$0 \cdot 2$ 
the oxidation of other substrates. These same dehydrogenases and other factors must be virtually absent from granules prepared in $\mathrm{NaCl}$. The particles prepared in sucrose show properties somewhere between those of these two preparations. To test the hypothesis that particles prepared in $\mathrm{NaCl}$ are unable to oxidize a substrate such as isocitrate because of factors lost to the supernatant, the latter was treated with ammonium sulphate ( $80 \%$ saturation) to precipitate most of the protein, and the resultant precipitate was dialysed and tested for ability to restore the ability of particles prepared in $\mathrm{NaCl}$ to oxidize isocitrate (Table 11). In the presence of both supernatant protein and DPN, the oxidation of isocitrate surpassed that of succinate. Omission of the supernatant protein abolished the oxidation of isocitrate, supporting the idea that a protein factor such as the dehydrogenase is missing from the granules. Omission of DPN decreased the oxidation to about one-third but the phosphorylation was little affected, suggesting that externally reduced DPN can be oxidized by the granules but that the oxidation is not accompanied by phosphorylation. This observation is in agreement with studies of animal mitochondria by Lehninger (1953). In the presence of DPN and supernatant protein some endogenous phosphorylation was observed, although 2-deoxyglucose and dialysed hexokinase were employed in this experiment in an effort to reduce endogenous reactions.

In contrast with isocitrate and other substrates poorly oxidized by unsupplemented particles prepared in $\mathrm{NaCl}$, lactate is oxidized readily (Table 12). Lactate oxidation with most preparations is comparable with the oxidation of succinate, and the $\mathrm{P} / \mathrm{O}$ values are only slightly lower. The addition of supernatant protein has no effect on the oxidation of succinate, but may increase the rate of oxidation of lactate although the degree of stimulation varies.

\section{Table 11. Oxidation of isocitrate}

Particles were prepared as described in Table 9 and assayed with $4.5 \mathrm{mg}$. of protein/vessel in a total volume of $1.6 \mathrm{ml}$. Where indicated, the vessels contained $40 \mu$ moles of isocitrate, $1.5 \mathrm{mg}$. of dialysed protein prepared from the supernatant fraction as described in the text, $0 \cdot 2 \mu$ mole of DPN and $40 \mu$ moles of succinate. 2-Deoxyglucose was substituted for glucose and hexokinase was dialysed free from glucose.

$\begin{array}{lccccc}\begin{array}{c}\text { Substrate } \\ \text { added }\end{array} & \begin{array}{c}\text { Supernatant } \\ \text { protein }\end{array} & \text { DPN } & \begin{array}{c}\mathrm{O}_{2} \text { uptake } \\ (\mu \text { g. atoms })\end{array} & \begin{array}{c}\mathrm{P}_{i} \text { uptake } \\ (\mu \text { moles })\end{array} & \text { P/O } \\ \text { None } & + & - & 0 & -0.19 & 0 \\ \text { None } & + & + & 0.2 & 0.31 & 1.5 \\ \text { iso-Citrate } & - & + & 0.2 & 0.2 & 1.0 \\ \text { iso-Citrate } & + & - & 0.67 & 0.58 & 0.87 \\ \text { iso-Citrate } & + & + & 1.95 & 0.68 & 0.35 \\ \text { Succinate } & + & - & 1.58 & 1.14 & 0.72\end{array}$

Table 12. Oxidation of lactate

Particles and assay procedure were as described in Table 11 except that $10 \mu$ moles of DL-lactate were added where indicated.

$\begin{array}{lcccc}\text { Substrate } & \begin{array}{c}\text { Supernatant } \\ \text { protein }\end{array} & \begin{array}{c}\mathrm{O}_{2} \text { uptake } \\ (\mu \mathrm{g} . \text { atoms })\end{array} & \begin{array}{c}\mathbf{P}_{\boldsymbol{i}} \text { uptake } \\ (\mu \mathrm{moles})\end{array} & \mathrm{P} / 0 \\ \text { None } & - & 0 & 0.15 & - \\ \text { None } & + & 0 & 0 & 0 \\ \text { Lactate } & - & 2.01 & 1.30 & 0.65 \\ \text { Lactate } & + & 2.72 & 1.60 & 0.59 \\ \text { Succinate } & - & 1.93 & 1.43 & 0.74 \\ \text { Succinate } & + & 1.96 & 1.43 & 0.73\end{array}$

Table 13. Uncoupling by 2:4-dinitrophenol of phosphorylation during oxidation of lactate and succinate

Particles and assay were as described in Tables 11 and 12 except that glucose was used as trapping system and no supernatant protein was added. 2:4-Dinitrophenol was added as indicated.

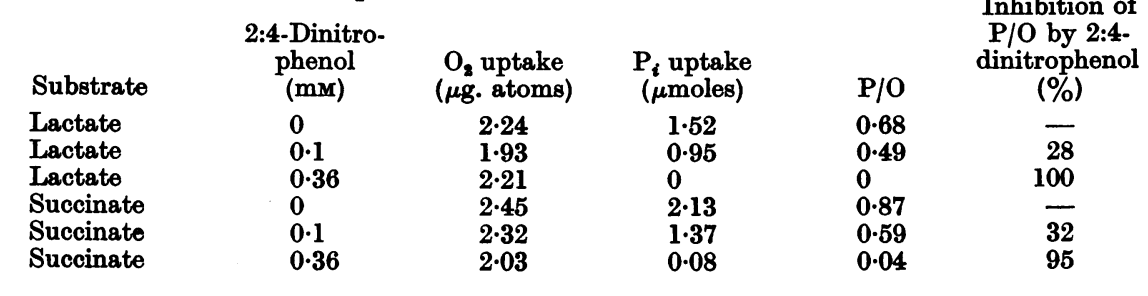

Inhibition of P/O by 2:4dinitrophenol

$0 \cdot 68$

0.49

$0 \cdot 87$

0.59

95 
The phosphorylation associated with the oxidation of lactate has a sensitivity to 2:4-dinitrophenol which corresponds closely to that associated with succinate oxidation (Table 13). Uncoupling is about $30 \%$ for both substrates at a concentration of $0.1 \mathrm{~mm}-2: 4$-dinitrophenol and is essentially complete at $0.36 \mathrm{~mm}$.

\section{DISCUSSION}

The present experiments establish that yeast cells contain sedimentable subcellular units able to couple phosphorylation with respiration. This finding strengthens the hypothesis that yeast cells contain organized respiratory particles similar to those found in animal and plant cells. The nature of the elements responsible for oxidative phosphorylation has not yet been established, although a major portion of the active material sediments in $15 \mathrm{~min}$. at centrifugal forces low enough to suggest that a considerable degree of organization may exist in the particulate fraction. The findings that the yeast particulates are able to carry out oxidative phosphorylation without supplementation by soluble components of the cell, and that the yeast system is completely uncoupled by 2:4dinitrophenol ally the yeast particles more with animal mitochondria than with microbial systems described previously.

The most obvious explanation of the rather low $\mathrm{P} / \mathrm{O}$ values obtained for succinate oxidation by yeast granules is that the particles have been damaged during isolation and are therefore not exhibiting optimal phosphorylation. An alternative explanation is that the $\mathrm{P} / \mathrm{O}$ value for succinate oxidation in yeast is 1 rather than 2. In a large number of experiments with a wide variety of preparative and assay procedures, very few $P / O$ values have exceeded 1 ; further, a small part of the observed phosphorylation may not be linked to respiration. It is interesting to recall that Slater (1953) proposed that the $\mathrm{P} / \mathrm{O}$ value for succinate oxidation in insect muscle was 1.

The failure in the present experiments to demonstrate an obligatory coupling of oxidation and phosphorylation can also be explained by assuming that the particles are not isolated in their native state, but the possibility must also be considered that no obligatory coupling exists in yeast.

It is possible that the yeast particles represent a mixture of active and inactive units. This would explain the low $P / O$ values but it is difficult to see why such a mixture would not show some degree of obligatory coupling of oxidation and phosphorylation unless there is interaction between the two species of particles.

Phosphorylation associated with a flavin-linked lactate oxidation has not been described pre- viously. Lactic dehydrogenase in yeast has been shown by Bach, Dixon \& Zerfas (1946) and Appleby \& Morton (1954) to be a flavo-haemoprotein with many properties analogous to the succinic dehydrogenase of heart. When considered together with the present studies, the presence in yeast of a lactoxidase unit as well as a succinoxidase unit can be postulated.

\section{SUMMARY}

1. Washed particulate fractions obtained by differential centrifuging from baker's yeast disintegrated by high-speed reciprocal shaking with glass beads show phosphorylation coupled to the oxidation of succinate and lactate.

2. Phosphorylation is dependent on the presence of an adenosine triphosphate-trapping system, yields glucose 6-phosphate as the major product and is completely uncoupled by 2:4-dinitrophenol.

3. Adenosine diphosphate is the only substance tested capable of acting as a phosphate acceptor; the other nucleoside diphosphates and adenosine monophosphate are completely inactive.

4. The $P / O$ values observed during succinate oxidation generally range from 0.6 to 0.9 and phosphorylation is not obligatorily coupled to respiration.

5. Succinate is oxidized mainly or entirely to fumarate and malate.

6. The oxidation of substrates other than succinate or lactate is dependent upon the nature of the disintegration procedure and subsequent isolation procedure.

The authors are grateful to Mr Robert Hsu for valuable assistance in carrying out several of the experiments above. One of us (M. F.U.) carried out part of this work during the tenure of a Fulbright Research Scholarship. The work was supported in Cleveland in part by Contract no. AT-(30-1)1050 with the Atomic Energy Commission and in part by the Elisabeth Severance Prentiss Foundation and in Adelaide in part by the Rockefeller Foundation and in part by National Health and Medical Research Council (Australia) grants.

\section{REFERENCES}

Appleby, C. A. \& Morton, R. K. (1954). Nature, Lond., 178, 749.

Bach, S. J., Dixon, M. \& Zerfas, L. G. (1946). Biochem. J. 40, 229.

Berger, L., Slein, M. W., Colowick, S. P. \& Cori, C. F. (1946). J. gen. Physiol. 29, 379.

Brodie, A. F. \& Gray, C. T. (1956a). J. biol. Chem. $219,853$. Brodie, A. F. \& Gray, C. T. (1956b). Biochim. biophys. Acta, $19,384$.

Cooper, C. \& Lehninger, A. L. (1956). J. biol. Chem. 219, 489.

Cramer, F. (1955). J. Franklin Inst. 253, 277.

Cross, R. J., Taggart, J. V., Covo, G. A. \& Green, D. E. (1949). J. biol. Chem. 177, 655. 
Hartman, P. E. \& Liu, C. (1954). J. Bact. 67, 77.

Herbert, E., Potter, V. R. \& Takagi, Y. (1955). J. biol. Chem. 213, 923.

Hunter, F. E. jun. \& Ford, L. (1955). J. biol. Chem. 216, 357.

Kornberg, A. (1950). J. biol. Chem. 182, 805.

Lehninger, A. L. (1953). Harvey Lect. 49, 176.

Lindegren, C. C. (1949). The Yeast Cell, its Genetics and Cytology. St Louis: Educational Publishers.

Linnane, A. W. \& Still, J. L. (1955). Arch. Biochem. Biophys. 59, 383.

Lohmann, K. \& Jendrassik, L. (1926). Biochem. Z. 178, 419.

Maley, G. F. \& Plaut, G. W. E. (1953). J. biol. Chem. 205, 297.

Massey, V. (1955). In Methods in Enzymology, vol. 1, p. 729. Ed. by Colowick, S. P. \& Kaplan, N. O. New York: Academic Press Inc.

Mudd, S., Brodie, A. F., Winterscheid, L. C., Hartman, P. E., Beutner, E. H. \& McLean, R. A. (1951). J. Bact. $62,729$.

Nossal, P. M. (1953). Aust. J. exp. Biol. med. Sci. 31, 583.
Nossal, P. M. (1954). Biochem. J. 57, 62.

Nossal, P. M., Keech, D. B. \& Morton, D. J. (1956a), Biochim. biophys. Acta, 22, 412.

Nossal, P. M., Keech, B. \& Utter, M. F. (1956b). Fed. Proc. 15, 321.

Pinchot, G. B. (1953). J. biol. Chem. 205, 65.

Pinchot, G. B. \& Racker, E. (1951). In Phosphorus Metabolism, vol. 1, p. 366. Ed. by McElroy, W. D. \& Glass, B. Baltimore: Johns Hopkins Press.

Racker, E. (1950). Biochim. biophys. Acta, 4, 20.

Robinson, R. W. \& Hogden, C. G. (1940). J. biol. Chem. 135, 707.

Slater, E. C. (1953). Nature, Lond., 172, 975.

Slater, E. C. \& Cleland, K. W. (1952). Nature, Lond., 170, 118.

Slonimski, P. P. \& Ephrussi, B. (1949). Ann. Inst. Pasteur, 77, 47.

Tissières, A. \& Slater, E. C. (1955). Nature, Lond., 176, 736.

Utter, M. F. \& Kurahashi, K. (1954). J. biol. Chem. 207, 787.

Woodward, G. E. \& Hudson, M. T. (1955). J. Franklin Inst. 259, 543.

\title{
Metabolism of Polycyclic Compounds
}

\begin{abstract}
12. AN ACID-LABILE PRECURSOR OF 1-NAPHTHYLMERCAPTURIC ACID AND NAPHTHOL: AN $N$-ACETYL-S-(1:2-DIHYDROHYDROXYNAPHTHYL)-L-CYSTEINE*
\end{abstract}

\author{
By E. BOYLAND AND P. SIMS \\ Chester Beatty Research Institute, Institute of Cancer Research: Royal Cancer Hospital, Fulham Road, \\ London, S.W. 3
}

(Received 8 August 1957)

The presence of acid-labile precursors of mercapturic acids in the urines of animals dosed with bromobenzene and chlorobenzene was first noticed by Baumann \& Preusse (1879) and Jaffe (1879). In studying the metabolism of naphthalene in rats and rabbits, Boyland \& Wiltshire (1953) observed a metabolite in the urine which gave the colour reactions of l-naphthol, but which was not extracted from neutral solution by ether. This socalled 'ether-insoluble 1-naphthol' was not present in the urine of animals dosed with 1-naphthol. In these experiments the excreted 1-naphthol was estimated colorimetrically, either by coupling with diazotized $p$-nitroaniline or by interaction with 2:6-dichloroquinonechloroimide. In both methods of estimation the urine was acidified before the addition of the reagents.

In a further investigation Boyland \& Solomon (1956) estimated a number of the metabolites of naphthalene by measurement of the areas of the spots produced by the various metabolites on paper chromatograms. In the course of this work

* Part 11: Boyland \& Sims (1957). a method was developed for the determination on chromatograms of 1-naphthylmercapturic acid (I), first isolated by Bourne \& Young (1934), depending on the pink fluorescence seen in ultraviolet light in the presence of ammonia. It was noticed that the urines of rats and rabbits treated with naphthalene contained little or no 1-naphthylmercapturic acid, but that after acidification of the urines the acid was liberated from a precursor (Solomon, 1954).

Knight \& Young (1957) have recently detected the presence of acid-labile mercapturic acid precursors (for which they propose the name premercapturic acids) in the urine of animals after the administration of benzene, anthracene, fluorobenzene, chlorobenzene, bromobenzene and iodobenzene, as well as with naphthalene. They also noticed that benzyl chloride was excreted directly as the corresponding mercapturic acid after administration to animals.

It has now been shown (Boyland, Sims \& Solomon, 1957) that the 'ether-insoluble 1naphthol' and the acid-labile precursor of 1 naphthylmercapturic acid are the same substance, treatment of the urine with mineral acid giving 